\title{
A CLOUD COMPUTING PLATFORM TO SUPPORT DIGITAL HERITAGE APPLICATION USING A SERVICE-ORIENTED APPROACH
}

\author{
Su Yang ${ }^{1}$, Miaole Hou ${ }^{2,3,}{ }^{*}$, Pengpeng Huo ${ }^{2,3,5}$, Aiqun $\mathrm{Li}^{3,4}$, Lili Jiang ${ }^{6}$ \\ ${ }^{1}$ North China Institute of Computing Technology, Beijing 100083, China - cinder0711@hotmail.com \\ ${ }^{2}$ School of Geomatics and Urban Spatial Informatics, Beijing University of Civil Engineering and Architecture, Beijing 102616, \\ China - houmiaole@bucea.edu.cn; \\ ${ }^{3}$ Beijing Advanced Innovation Center for Future Urban Design, Beijing University of Civil Engineering and Architecture, Beijing \\ 100044, China; \\ ${ }^{4}$ School of Civil and Transportation Engineering, Beijing University of Civil Engineering and Architecture, Beijing 102616, China; \\ ${ }^{5}$ Beijing Institute of Surveying and Mapping, Beijing 100038, China; \\ ${ }^{6}$ Beijing Digsur Science and Technology Co. Ltd., Beijing 100012, China
}

Commission VI, WG VI/4

KEY WORDS: Cultural heritage, Digital heritage, Cloud platform, Service-oriented, System architecture

\begin{abstract}
:
Since the digital technologies emerge, digital heritage has become an integral part of the world's cultural heritage under the leadership of UNESCO. With the development of digitization and accumulation of data, the digital information processing system for cultural heritage keeps updating. However, there still exist the problems of low information integration degree and weak information sharing ability, severely restricting the promotion and integration of cultural heritage and society. This paper proposes a digital cultural heritage cloud platform, where basic data service, knowledge service, engineering application, visual exhibition were realized through HTTP request. This platform completely encapsulated a large number of cultural heritage data processing algorithms. Accordingly, a cultural heritage data management system, a cultural heritage knowledge construction and application system, a cultural heritage display, analysis and evaluation system, and a cultural heritage microenvironment index monitoring system were embedded in this platform. In addition, the platform provided API for professional customized development to provide effective support. This platform can be flexibly adapted and extended, laying solid foundation for digital information sharing of cultural heritage.
\end{abstract}

\section{INTRODUCTION}

Since the field of cultural heritage protection entered the digital era, the daily updates obtained from the Internet, the various types of advanced sensors, as well as the precious historical archives in the museum, have made it possible to record all aspects of cultural heritage in a comprehensive way (Münster et al., 2016). It is undoubtedly that today's digital data sources with high accuracy, high time efficiency and large space-time span enable cultural heritage to be stored in the digital format, (e.g., CD and disk), achieving persistent data storage (Tobiasz et al., 2019). Meanwhile, the digitally stored data provides valuable basis for protecting cultural heritage and conducting research in this filed (Hoon et al., 2019). However, the explosive growth of data poses certain challenges for data analysis and processing capabilities. There still exist bottlenecks in translating data into more universal information or knowledge, which serves the management departments, research institutions, museum industry, education, and the public related to cultural heritage (Hou et al., 2018). Since the raw data express the objective information of cultural heritage, when it comes to a variety of complex practical applications, it is difficult for general users to discover the internal relationship from the messy data, so as to effectively extract the desired information. Moreover, the cultural heritage usually owns a history of thousands of years and coexists with human civilization, involving a large amount of historical, social, economic and cultural values, which are difficult to measure from single-source information. As such, it is urgent to organize and correlate the relevant multi-source data accurately and efficiently. Potential solutions include extracting the key information according to the characteristics of different types of data, acquiring the cultural relics and the surrounding environmental information in a real-time manner, and visualizing them in various formats. In this way, a variety of extensible and customizable solutions can be further proposed to meet different application requirements. With the development of computer technology, the cloud computing platform, acting as the core technology to promote the resource sharing and the development and utilization of digital cultural heritage, is an inevitable choice to cope with the current situation.

This paper proposes a cloud platform for processing largevolume and multi-type information related to digital cultural heritage- by providing web services. The proposed cloud platform enables cultural heritage knowledge construction, data organization and storage, feature extraction, real-time monitoring of cultural heritage data distribution, and other services. The platform provides information service based on the HTTP request by users, so as to improve the ability of realtime updating, sharing, and processing of digital cultural heritage information. In addition, the platform can better integrate resources, establish management of some seemingly irrelevant information through knowledge network, and promote intelligent retrieval and data analysis.

The purpose of this study is to design and develop a cloud platform integrating multiple digital cultural heritage applications through providing web services, including a database cluster built from a variety of databases. The rest of this article is organized as follows. Section 2 investigates the 
applications concerning digital cultural heritage as well as the existing work in this field. The architecture design of our cloud platform is introduced in Section 3. Section 4 discusses the implementation of the platform and the four applications deployed on the platform. Finally, the contributions and the future work are summarized in Section 5.

\section{DIGITAL HERITAGE AND RELATED WORK}

\subsection{Digital Heritage Application}

In 2003, in Paris, UNESCO proposed the definition of digital heritage (UNESCO, 2004):

The digital heritage consists of unique resources of human knowledge and expression. It embraces cultural, educational, scientific and administrative resources, as well as technical, legal, medical and other kinds of information created digitally, or converted into digital form from existing analogue resources. Where resources are "born digital", there is no other format but the digital object.

The purpose of preserving digital cultural heritage is not only limited to the persistence of historical archives, it cannot be ignored that the use of these digital resources can provide more beneficial help for the sustainable development of cultural heritage. Researchers in this field have indeed made great efforts. A large number of non-contact sensor technologies made the three-dimensional (3D) digital archives of cultural heritage accurate and convenient (Bakirman et al., 2020). Based on the digital archives, engineering drawings such as orthographs, sections, etc. can be generated to assist in the conservation of cultural heritage (Yilmaz et al., 2007). Using digital heritage to infer the original appearance of history does not cause secondary damage to cultural heritage. Zeng et al. (2020) predicted the missing information of a large area through the electronic image of ancient paintings, which was used for the virtual restoration of mural colors. Digital data analysis of cultural heritage is gradually shifting from traditional statistical analysis to machine learning (Fiorucci et al., 2020). Another example is using photogrammetry to build 3D models of archaeological sites, and proposing a technique named as "quasi-mixed reality". A case study testing such technique was conducted at the Courferri Archaeological site of Ancient Phalasarna on western Crete (Liestøl, Hadjidaki, 2020). Digital heritage archives used GIS (Campanaro et al., 2016) and heritage Building Information Modeling (Gigliarelli et al., 2017) technology to produce products for the protection of cultural heritage, which were mainly used in the visual expression and information management of cultural heritage. These technologies and methods are great convenience brought by digital heritage.

\subsection{Related Work}

In order to make better use of digital heritage, researchers have proposed many application systems by using emerging technologies. A CHPC (Cultural Heritage Preservation and Conservation) system was proposed to regulate the microenvironment in the museum, where technologies such as Internet of things, artificial intelligence, and semantic web were applied (Anatoly et al., 2019). A novel DHR (Digital Heritage Resources) implementation framework called DISPLAYS (Digital Library Services for Playing with Antiquity and Shared Heritage) was presented to manage diverse and complex digital legacy objects (Al-Barakati et al., 2014). A project to promote collaboration between cultural heritage participants and organizers was developed in the digital city of Thessaloniki,
Greece, to improve the city's cultural heritage management system (Psomadaki et al., 2019). Regarding the fact that European libraries, museums and archives had the problem of poor public access performance, Machidon et al. (2020) improved the accessibility and search accuracy of digital resources through a variety of intelligent and advanced network technologies. A VR/AR system was developed in the ArkaeVision project that enabled people to enjoy the charm of cultural heritage in a more innovative and immersive way (Bozzelli et al., 2019).

Although these systems have great application significance in digital heritage, the independent tools lack the ability to effectively integrate multiple resources. Aiming at preserving the sustainable development of cultural heritage and disseminating culture more effectively, researchers should work together to achieve a higher level of information sharing and data interaction in spite of the certain restrictions on copyright. Therefore, it is urgent to design a more general system architecture meeting various requirements and build a universal cloud platform targeting cultural heritage.

\section{DESIGH AND DEVELOPMENT METHODOLOGY}

\subsection{Functional Design}

The function of the platform was determined by accommodating users' requirements. Currently, in the field of digital cultural heritage, management departments mainly focus on the macro analysis of information, health monitoring, and analysis reports, to aid in policy making and decision-making. Museum organizations are concerned with data archiving, information management of exhibits, and visual Tours. Data producers need to efficiently organize and store the collected multi-source data, including massive point clouds, images, text data, and real-time transmission data from monitoring sensors. The researchers, however, hope to automate the extraction of features of interest to reduce repetitive labour. The public prefers immersive cultural experience and knowledge learning. Despite that, there are some common needs, such as online browsing of images, audios, videos, high-precision 3D models and other data, as well as efficient intelligent retrieval, and intelligent Q\&A form to solve some basic problems. As shown in Figure 1, the requirements analysis module presents the major potential users and the four business requirements in the digital cultural heritage, based on which the functional requirements are refined.

\subsection{Cloud platform architecture}

The overall technical architecture of the digital cultural heritage cloud platform is shown in Figure 2. The architecture is divided into four levels from bottom to top, namely the cloud infrastructure platform layer, the cloud platform data resource layer, the cloud platform business service layer, and the application software layer. The details of each layer are as follows.

- The cloud platform infrastructure layer mainly includes the hardware and supporting software environment required by the cloud platform. The physical environment mainly involves computing, storage, and network facilities, based on which the virtualization server, network and storage resources pool are realized. The operating systems and management software are also engaged to support the cloud platform infrastructure.

- The role of the cloud platform data resource layer is to realize the safe storage of data and persist multi-source heterogeneous cultural heritage data. It is widely acknowledged that relational database is responsible for the structured storage of data, and spatial database is mainly used for the storage of spatial information. Thus, a database cluster consisting of multiple 


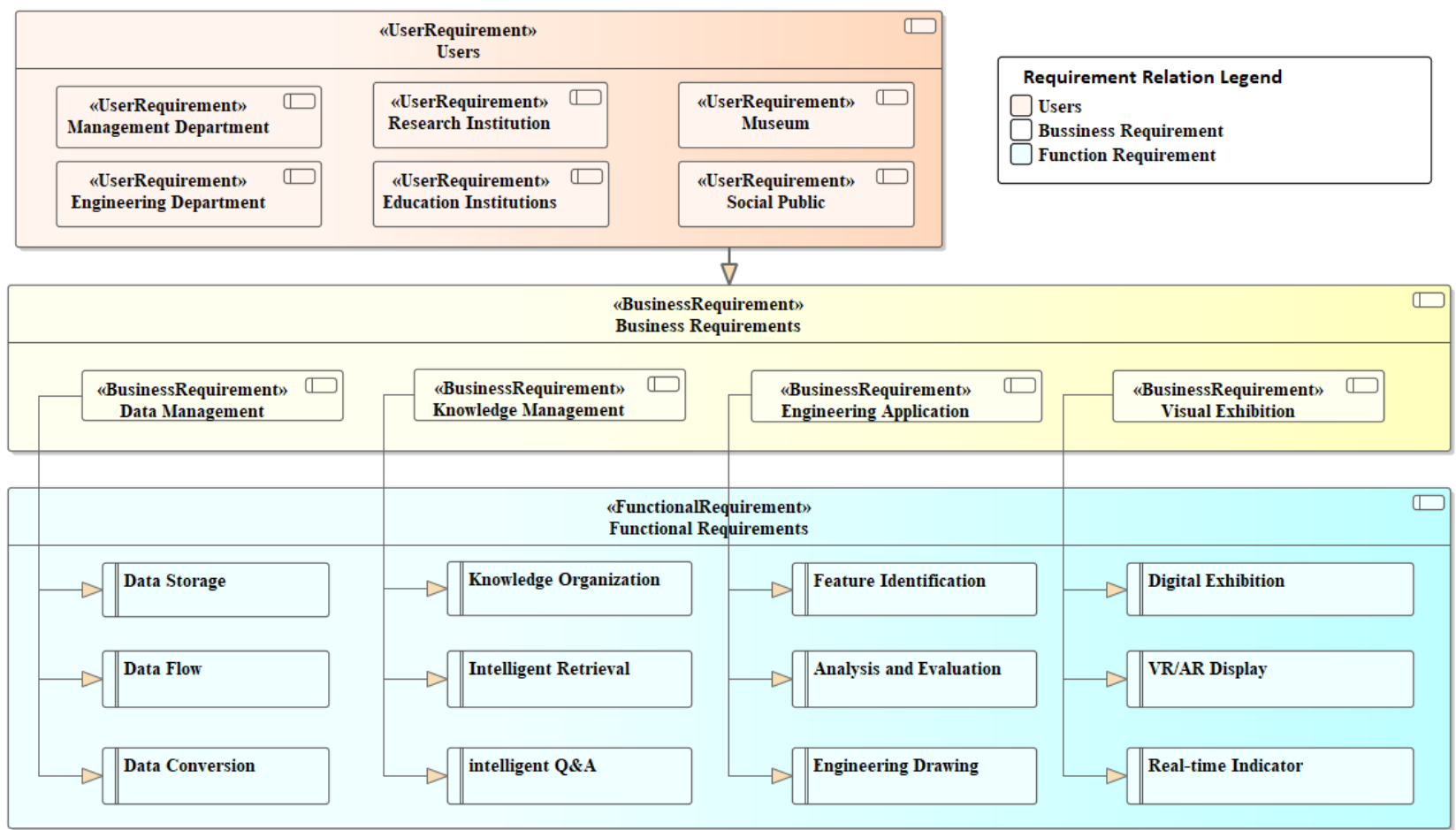

Figure 1. User, business, and functional module mapping

types of databases are constructed for such purposes to manage semantic data, spatial data, real-time sensor data, and bulk file data.

- Business service layer can provide platform users with data services, knowledge services, engineering services and visual display services in the field of cultural heritage. The various services in this layer encapsulate their own unique methods to handle the HTTP requests sent by the application layer, complete the calculation through the interaction with the data resource layer, and return the results to the application layer.

- The platform application layer is a series of application software, of which the functions are achieved through a unified service interface. On top of providing generic software, custom development can be done through the interfaces provided by cloud services.

\section{PROTOTYPING AND IMPLEMENTATION}

\subsection{System implementation framework}

The architectural design of the system is shown in Figure 3. This platform is based on amazon commercial cloud foundation platform. Four core digital cultural heritage services are deployed (see the cloud service layer in Figure 3), including data processing services, knowledge management services, engineering application services and visual exhibition services.

With Hadoop as the core, the Oracle Spatial Spatial database is used for the data processing service. Oracle $11 \mathrm{~g}$ relational database, Neo4j, and a large number of cloud storage spaces are integrated to build a server cluster to realize distributed storage of massive data of digital cultural heritage. The service mainly provides the data access function, as well as the format conversion function of all kinds of data.

Natural language processing technology is the core of knowledge management service, which encapsulates the extraction of triples, the construction of knowledge network, and the construction of knowledge map with syntax dependency. On this basis, it also provides the intelligent search and intelligent question and answer service for the cultural heritage field.

The core of engineering application service is a series of feature extraction algorithms and big data analysis and processing algorithms based on images, point clouds and grid models. Among them, the purpose of feature extraction is to quickly extract the contents that can represent the key characteristics of cultural heritage and provide support for engineering applications. Encapsulating these algorithms mainly involves the Web service version encapsulated twice on the basis of OpenCV, point cloud segmentation, key component identification, skeleton line extraction, cultural relic surface roughness calculation, model quantization analysis, and automatic geometric Mosaic algorithm. With regard to the big data analysis, cluster, segmentation, outlier analysis and prediction analysis are provided. Based on these algorithms, it provides quantitative comparative analysis of cultural heritage, automatic report generation, engineering drawing and other practical functions.

Digital exhibition service adopts WebGL as the core technology, which encapsulates the 3D rendering engine based on web, and the automatic construction function of virtual reality scene on the basis of Unity 3D. In addition, the cultural heritage real-time monitoring data index collection service has been established to complete data distribution through RTI DDS.

Finally, based on these services, four basic application platforms are constructed, namely digital cultural heritage data management system, cultural heritage knowledge construction and application system, cultural heritage display, analysis and evaluation system, and cultural heritage micro-environment monitoring system. 

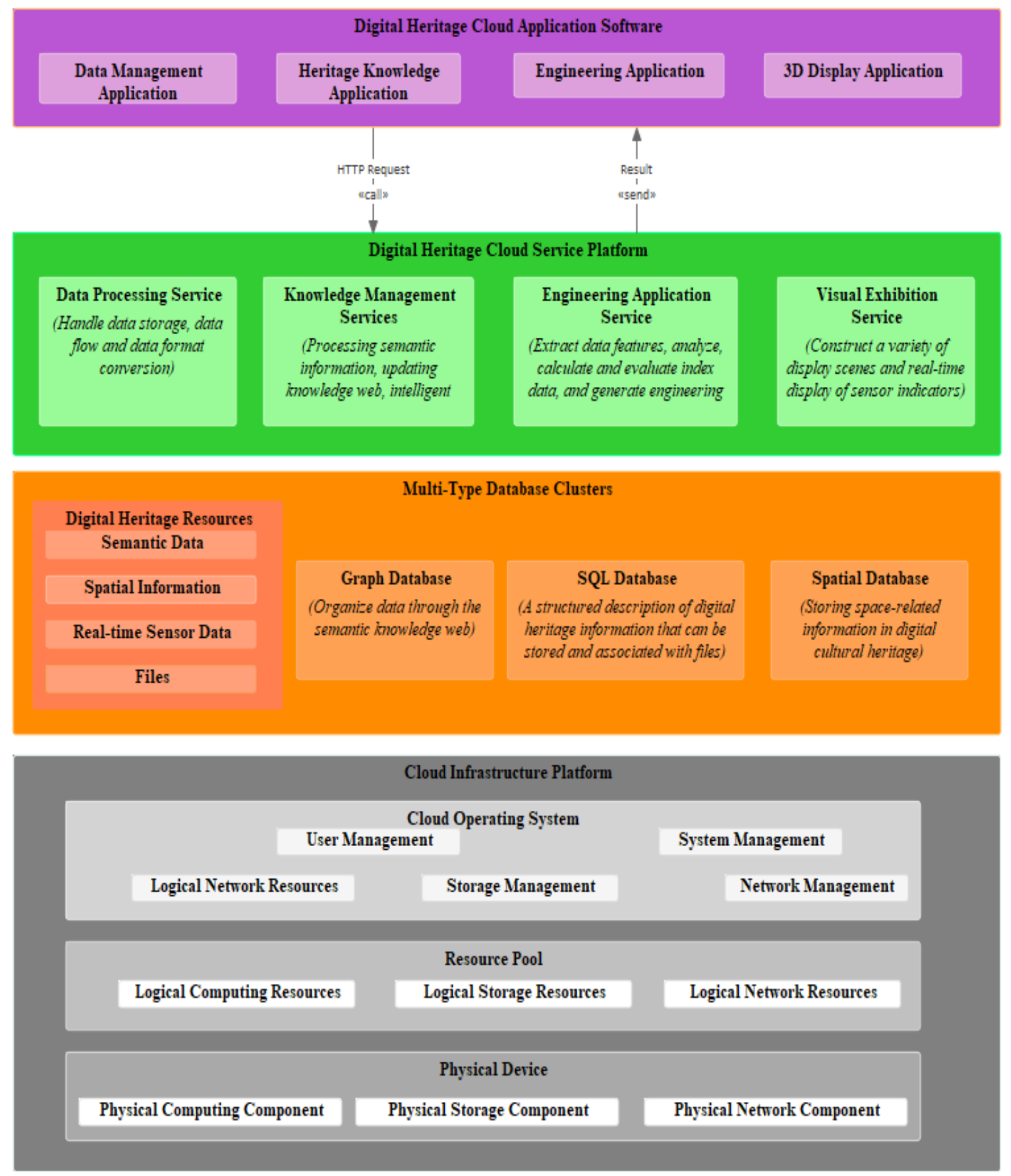

Figure 2. Digital heritage cloud platform architecture design 


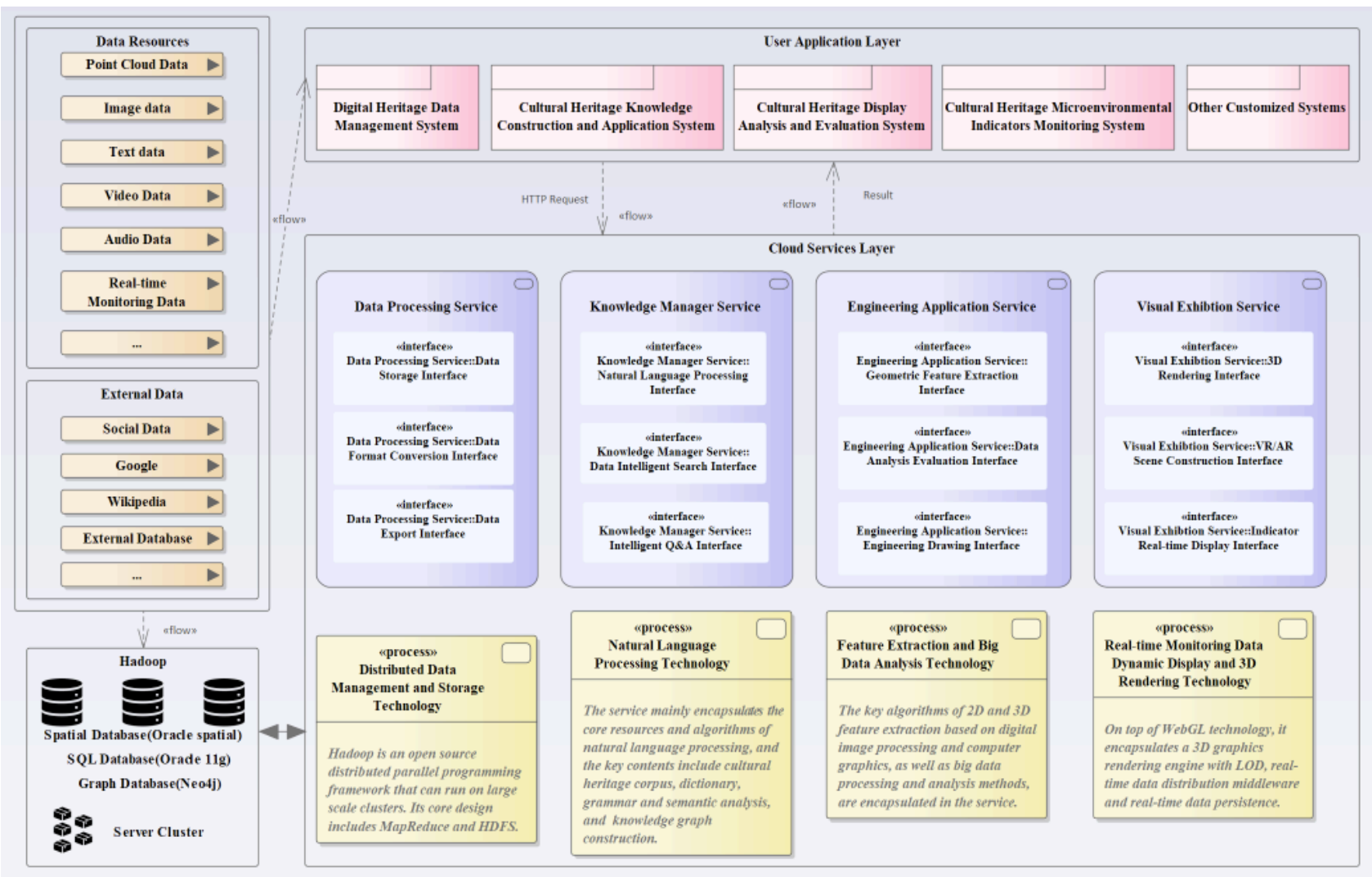

Figure 3. Digital heritage cloud platform implementation architecture

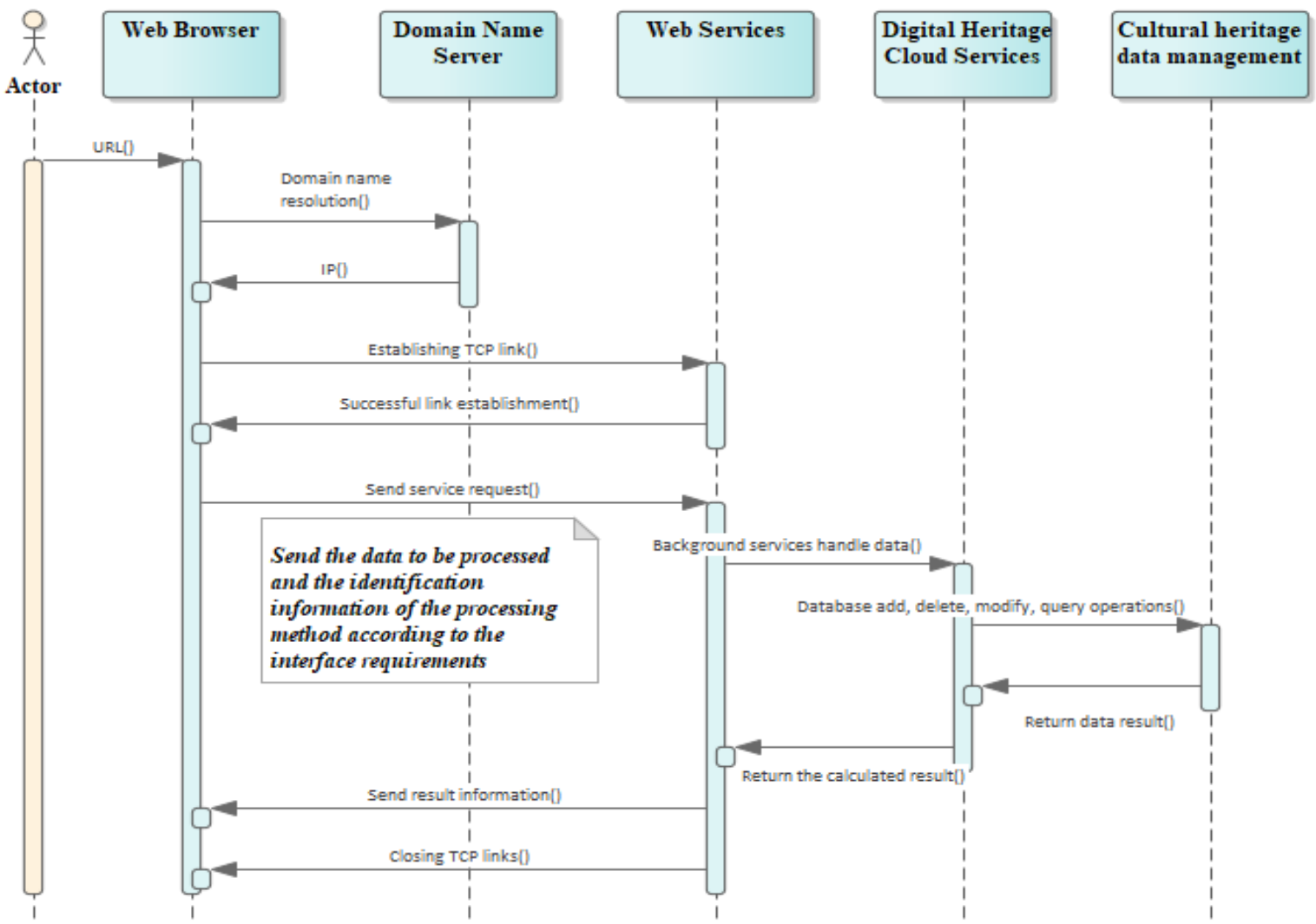

Figure 4. HTTP request processing sequence diagram 


\subsection{Cloud Services APIs}

\subsubsection{API call sequence}

An HTTP request is a request message from the client to the server. This includes the method of requesting the resource in the first line of the message, the identifier of the resource, and the protocol used. In this platform, the data to be processed and the method identification to be processed are sent to the web service side through the HTTP request, and the cloud service invokes the algorithm encapsulated in the service according to the corresponding method identification. In this process, there seems to be an interaction with the database. Finally, the calculated results are returned to the client in Json format and displayed. A typical invocation sequence is shown in Figure 4.

\subsubsection{Public interface description}

In this platform, the server-side public interface is invoked via HTTP request, as shown in Table 1.

\begin{tabular}{|c|c|c|c|}
\hline $\begin{array}{l}\text { Parameter } \\
\text { name }\end{array}$ & $\begin{array}{l}\text { Parameter } \\
\text { type }\end{array}$ & Necessary & Parameters describe \\
\hline userId & String & $\mathrm{Y}$ & User ID \\
\hline timestamp & String & $\mathrm{Y}$ & $\begin{array}{l}\text { Current timestamp: } \\
\text { yyyyMMddHHmmss }\end{array}$ \\
\hline sign & String & $\mathrm{Y}$ & Digital signature \\
\hline servicename & String & $\mathrm{Y}$ & Service name \\
\hline functionIden & String & $\mathrm{Y}$ & Function Id \\
\hline data & String & $\mathrm{Y}$ & Data to be processed \\
\hline datatype & String & $\mathrm{Y}$ & Data Type \\
\hline batchId & String & $\mathrm{Y}$ & $\begin{array}{l}\text { Customize message } \\
\text { ID }\end{array}$ \\
\hline addserial & String & $\mathrm{N}$ & Extend code \\
\hline
\end{tabular}

\subsubsection{Interface return value description}

The detailed description of the return value of the call interface request is presented in Table 2 .

\begin{tabular}{|lll|}
\hline $\begin{array}{l}\text { Parameter } \\
\text { name }\end{array}$ & $\begin{array}{l}\text { Parameter } \\
\text { type }\end{array}$ & Parameters describe \\
\hline code & int & $\begin{array}{l}\text { 0 is success and the rest are error } \\
\text { code } \\
\text { The resulting content is in json } \\
\text { format }\end{array}$ \\
\hline
\end{tabular}

Table 2. Interface return value description

\section{APPLICATIONS}

\subsection{App1ication 1: Digital cultural heritage data management system}

The data management system is mainly used by the cultural heritage digital collection team and document management department. They are able to manage and store digital cultural heritage data in the form of documents. Among them, the way of distributed storage is adopted for the bulk file. Figure 5 shows the login interface and file upload of a data management system developed for a cultural heritage conservation project.

\subsection{App1ication 2: Cultural heritage knowledge construction and application system}

The knowledge management system can realize the correlation between data and knowledge, as well as more efficient and intelligent retrieval forms and intelligent questions and answers for the knowledge graph of various cultural heritage fields and the public. Figure 6 shows the knowledge map of a Buddha statue constructed by using natural language processing technology through the construction of triplet model, semantic analysis and other processing

\subsection{App1ication 3: Cultural heritage display, analysis and evaluation system}

The cultural heritage exhibition, analysis and evaluation system is mainly targeted at the cultural heritage protection workers. It provides feature information, engineering drawings and evaluation analysis for engineering applications. Figure 7 shows some application scenarios for the system.

\subsection{App1ication 4: Cultural heritage micro-environment monitoring system}

Cultural heritage microenvironment monitoring system is mainly applied for cultural heritage monitoring. The system can monitor environment of cultural heritage sites of sensor data is sent back to the data centre for real-time display, and provides such as the line chart, pie chart, bar chart and radar map, scatter plot, heat is trying to wait for a variety of visual representation scheme. Figure 8 shows the statistics of the sensor and the realtime monitoring data.

\section{CONCLUSION}

This paper proposes a cloud computing platform for web service-oriented application of facial cultural heritage. The contribution of this platform in the field of cultural heritage is to build a bridge between the massive and chaotic digital cultural heritage data and users from different application directions. An integrated relational, non-relational and spatial database data management and storage server cluster was built. Four services were deployed in the cloud platform, which can solve the basic problems of data management, knowledge management, engineering application and visualization. The correctness and practicability of the system architecture were illustrated by four applications. The platform extension capability was provided through the network service API interface. Therefore, this platform breaks the technical barrier between the explosive growth of data and the application of cultural heritage data and provides a good reference and application example for information sharing and cultural communication. 


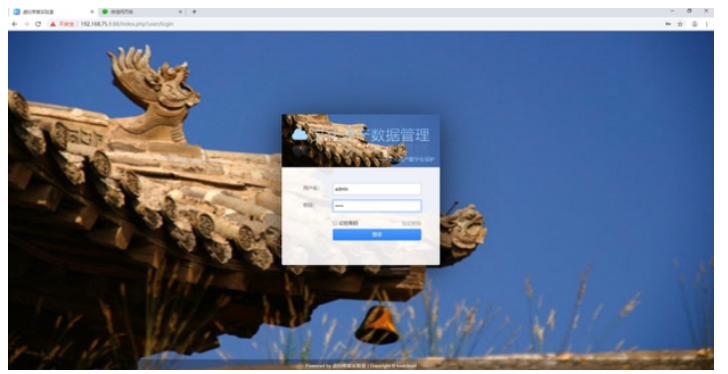

(a)

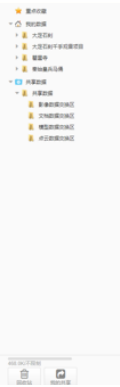

Figure 5. A cultural heritage data management system

(a) User management login interface (b) file upload and online view

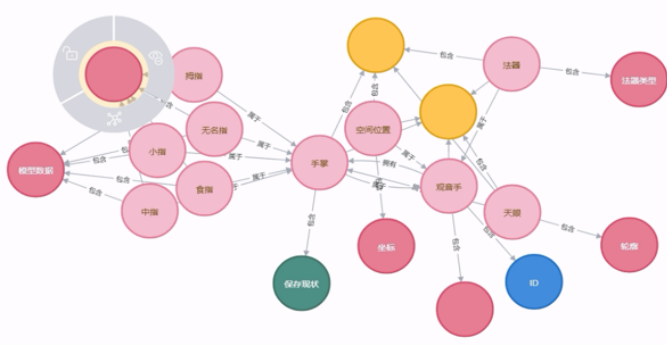

(a)

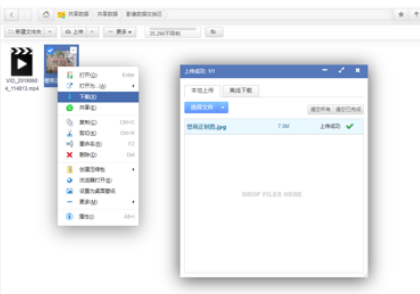

(b)

Figure 6. A knowledge graph built through knowledge services

(a)Automatically generated knowledge graph (b)The expert reviewed the knowledge graph

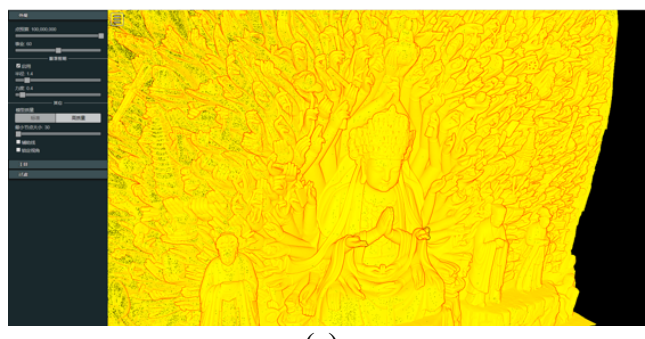

(a)

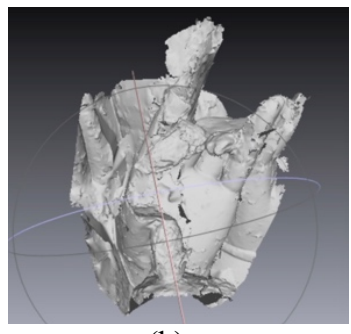

(b)

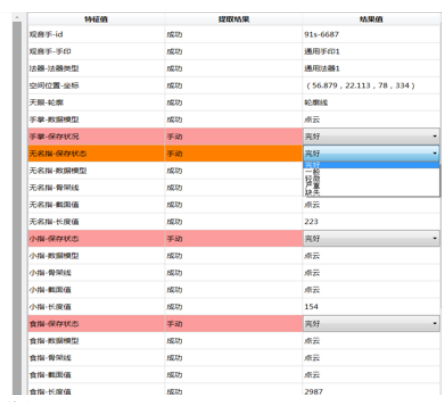

b)

Figure 7. A knowledge graph built through knowledge services

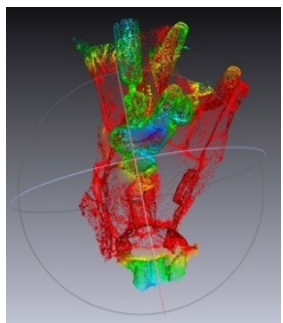

(c)

(a) A high precision 3D display of a Buddha statue (b) A 3D model of a damaged sculpture (c) Quantitative analysis of cultural relics before and after repair

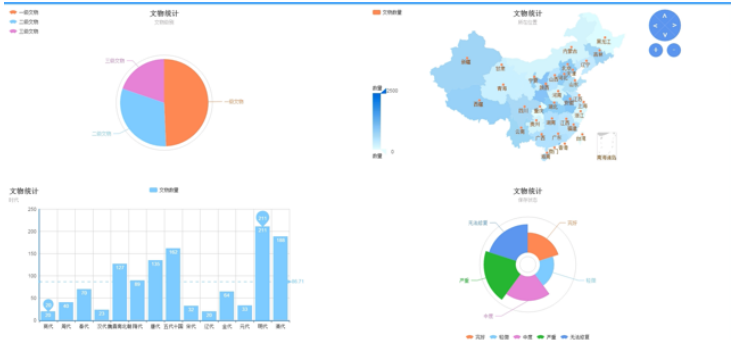

(a)

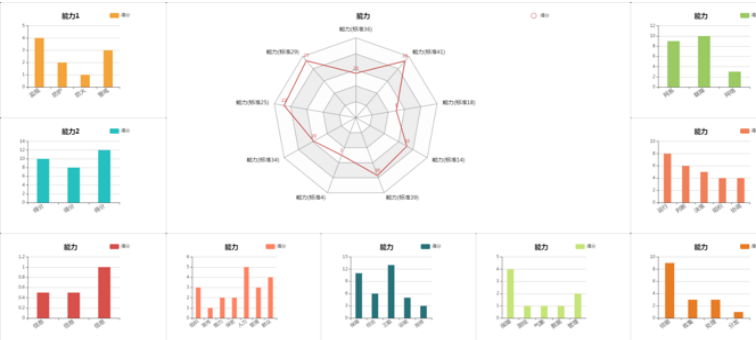

(b)

Figure 8. Sensor real-time monitoring of an overall statistics with indicators monitoring

(a) Show the calculation of the total accumulation index (b)The real-time update of each index 


\section{REFERENCES}

Al-Barakati, A., White, M., Patoli, Z., 2014. The application of workflow management to digital heritage resources. International Journal of Information Management 34, 660-671. https://doi.org/10.1016/j.ijinfomgt.2014.06.003

Anatoly, K., Rezeda, K., Maxim, L., Feng, L., Hu, L., Chen, M., Igor, B., 2019. CHPC: A complex semantic-based secured approach to heritage preservation and secure IoT-based museum processes. Computer Communications 148, 240-249. https://doi.org/10.1016/j.comcom.2019.08.001

Bozzelli, G., Raia, A., Ricciardi, S., De Nino, M., Barile, N., Perrella, M., Tramontano, M., Pagano, A., Palombini, A., 2019. An integrated VR/AR framework for user-centric interactive experience of cultural heritage: The ArkaeVision project. Digital Applications in Archaeology and Cultural Heritage 15, e00124. https://doi.org/10.1016/j.daach.2019.e00124

Campanaro, D.M., Landeschi, G., Dell'Unto, N., Leander Touati, A.M., 2016. 3D GIS for cultural heritage restoration: A "white box" workflow. Journal of Cultural Heritage 18, 321332. https://doi.org/10.1016/j.culher.2015.09.006

Bakirman, T., Bayram, B., Akpinar, B., Karabulut, M.F., Bayrak, O.C., Yigitoglu, A., Seker, D.Z., 2020. Implementation of ultra-light UAV systems for cultural heritage documentation. Journal of Cultural Heritage 1-11. https://doi.org/10.1016/j.culher.2020.01.006

Fiorucci, M., Khoroshiltseva, M., Pontil, M., Traviglia, A., Del Bue, A., James, S., 2020. Machine Learning for Cultural Heritage: A Survey. Pattern Recognition Letters 133, 102-108. https://doi.org/10.1016/j.patrec.2020.02.017

Gigliarelli, E., Calcerano, F., Cessari, L., 2017. Heritage Bim, Numerical Simulation and Decision Support Systems: An Integrated Approach for Historical Buildings Retrofit. Energy Procedia 133, 135-144. https://doi.org/10.1016/j.egypro.2017.09.379

Hoon, Y.J., Hong, S., 2019. Three-dimensional digital documentation of cultural heritage site based on the convergence of terrestrial laser scanning and unmanned aerial vehicle photogrammetry. ISPRS International Journal of GeoInformation 8. https://doi.org/10.3390/ijgi8020053
Hou, M., Yang, S., Hu, Y., Wu, Y., Jiang, L., Zhao, S., Wei, P., 2018. Novel method for virtual restoration of cultural relics with complex geometric structure based on multiscale spatial geometry. ISPRS International Journal of Geo-Information 7, 1-20. https://doi.org/10.3390/ijgi7090353

Liestøl G., Hadjidaki E., 2020. Quasi-Mixed Reality in Digital Cultural Heritage. Combining 3D Reconstructions with Real Structures on Location-The Case of Ancient Phalasarna. In: Kremers H. (eds) Digital Cultural Heritage. Springer, Cham. https://doi.org/10.1007/978-3-030-15200-0_29

Machidon, O.M., Tavčar, A., Gams, M., Duguleană, M., 2020. CulturalERICA: A conversational agent improving the exploration of European cultural heritage. Journal of Cultural Heritage 41, 152-165. https://doi.org/10.1016/j.culher.2019.07.010

Münster, S., Pfarr-Harfst, M., Kuroczyński, P., Ioannides, M., 2016. 3D Research Challenges in Cultural Heritage II : How to Manage Data and Knowledge Related to Interpretative Digital 3D Reconstructions of Cultural Heritage. https://doi.org/10.1007/978-3-319-47647-6

Tobiasz, Markiewicz, Łapiński, Nikel, Kot, Muradov, 2019. Review of Methods for Documentation, Management, and Sustainability of Cultural Heritage. Case Study: Museum of King Jan III's Palace at Wilanów. Sustainability 11, 7046. https://doi.org/10.3390/su11247046

UNESCO, 2004. Records of the General Conference - 32nd Session - Paris, 29 September to 17 October 2003 - Volume 1 Resolutions.https://unesdoc.unesco.org/ark:/48223/pf00001331 71

Yilmaz, H.M., Yakar, M., Gulec, S.A., Dulgerler, O.N., 2007. Importance of digital close-range photogrammetry in documentation of cultural heritage. Journal of Cultural Heritage 8, 428-433. https://doi.org/10.1016/j.culher.2007.07.004

Zeng, Y., Gong, Y., Zeng, X., 2020. Controllable digital restoration of ancient paintings using convolutional neural network and nearest neighbor. Pattern Recognition Letters 133, 158-164. https://doi.org/10.1016/j.patrec.2020.02.033 